\title{
LA CONSTRUCCIÓN DE NARRACIONES POPULARES: UN EJEMPLO DESDE SUS ELEMENTOS SIMBÓLICOS ${ }^{1}$
}

\author{
Bruno Cárdenas Maragaño*
}

\section{ANTECEDENTES}

Las narraciones populares forman parte de la memoria de los pueblos, en razón de ello constituyen un sustrato interesante de antecedentes históricoculturales en sus distintas expresiones, por ejemplo, las leyendas, mitos, cuentos, refranes, chascos, etc., que recogen las costumbres, creencias, saberes y rasgos comunitarios que dan cuenta de aspectos o situaciones de vida en un contexto de dinámicas recursivas de índole psicológica o de referentes sociológicos, axiológicos, entre otros. A nivel de las representaciones tenemos el teatro popular, las danzas, las fiestas religiosas, los dibujos o artesanías.

Se agrega a lo anterior, el conocimiento y variedad de percepciones que se relacionan con el entorno natural, social e ideológico que son parte constituyente del desenvolvimiento del hombre, todo lo cual conforma un mundo interrelacionado, dialogante, sociocomunicativo y reproductor de las tradiciones que se movilizan en ambientes étnicos, sociales y económicos muy disímiles $\mathrm{y}$, en muchos casos, en tensión permanente. Se trata de expresiones ricas en antecedentes, explicaciones e interpretaciones, mediante las cuales es posible rastrear aspectos clave de identidad y de un saber que, no obstante, pueda presentarse fantasiosa, legendaria o mitologizadamente, permitiendo dar cuenta de un conocimiento concreto y prolijo de la realidad y del modo cómo el sujeto se percibe a sí mismo, al mundo y a los demás.

Las narraciones orales, leyendas, adivinanzas, romances son, entonces, expresiones de la cultura y como tal son producciones contenidas de tradición y saberes generados con el tiempo, lo que significa dotarse de sucesos, acontecimientos, vicisitudes de todo orden que constituyen la realidad que el pueblo vivencia. En este sentido son producciones generadas, al menos, desde dos dimensiones: a) en su perspectiva cronológica y b) en las circunstancias de las experiencias vivenciales.

\footnotetext{
${ }^{1}$ Este trabajo forma parte de la ejecución del Proyecto Fondecyt $N^{\circ} 1120574$.
} 


\section{NARRACIONES ORALES}

Una pregunta de principio es plantearnos si es o no aceptable hablar de la existencia de una literatura oral a partir de narraciones orales, cuestión que para W. Ong no corresponde, pues significaría referirse a una cosa u objeto en términos de otra: "Considerar la tradición oral o una herencia de representación, géneros y estilos orales como 'literatura oral' es algo parecido a pensar en los caballos como automóviles con ruedas" (Ong, 20-21). Agrega en la idea anterior que significaría presentar la oralidad como una variante de la escritura. La expresión "literatura oral" fue acuñada por Paul Sébillot aplicada a la recopilación de manifestaciones de cultura popular de Bretaña en 1881; en el compendio se incorporaban, entre otros, cuentos, leyendas, proverbios, cantos, de la tradición oral y que en Ong corresponderían a sonorizaciones (voicings), correspondientes a la oralidad de contenido artístico. Ciertamente que esta última expresión releva la palabra. En un principio, se sabe, era el verbo, la palabra que iluminaba la oscuridad. En la Nada total emerge la palabra desde la boca divina; en el Popol Vuh se nos dice que no había nada, solo el mar y el cielo en su vastedad, ambos vacíos y entonces llegó la palabra: Tepeu y Gucumatz, lo creadores de la humanidad, ellos hablaron en la oscuridad, levantaron la tierra que estaba sumergida, crearon los animales, intentaron crear un ser obediente, primero lo intentaron de barro, luego madera, finalmente lo consiguieron gracias al maíz. Es decir, entre la palabra pronunciada y el acto no existía distancia alguna, toda vez que el hacer por medio de la palabra era atributo de los dioses.

Lo literario se define por la expresión narrativa, independientemente del medio mediante el cual se canalice, lo que, a su vez, permite acceder a la literatura popular y de las márgenes, la que puede ser oral o escrita, o bien, producto - como el ejemplo que se tratará en el presente artículo- de la transcripción de una narración oral recopilada, tal y como sucedió, por ejemplo, con los romances presentados para la lectura y el canto, ya sea con los pliegos sueltos o literatura de cordel, o literatura callejera, momento en el cual los textos adquieren eficacia y sentido mayor. El objetivo inicial de la escritura no consistió en reemplazar el sonido por lo visual, sino reforzar la oralidad, aun cuando ello significara una descarga de trabajo para la memoria y, acaso, un debilitamiento de ella, que es una clave para la oralidad.

No obstante lo anterior, es preciso referir que si bien la memoria es condición necesaria de la oralidad, su "reemplazo" por la escritura no la hace excluyente, al contrario, piénsese, por ejemplo, en la discursividad religiosa que es predominantemente oral, pero conviviendo con la escritura. No es casual que en el rito el texto sea leído en voz alta, momento en el cual la palabra cobra vida, lo que es muy importante, debido al propósito evangélico en el proceso de 
construcción de sentido, generándose un encuentro entre el mundo de la palabra y el mundo del lector; queremos entender que lo que vale para el lector, puede ser válido para el auditor.

Con certeza, el lenguaje es primordialmente oral y que es propio a todo pueblo, a toda cultura que haga de él un uso estético, de momento que todos poseen sus leyendas, canciones, cuentos, mitos, que pueden ser asimilables al concepto de literatura. Resulta necesario precisar que no es una misma cosa la oralidad con literatura oral, aun cuando ambas son constructoras de recepciones, pues contienen relatos y experiencias. Sin embargo, es menester considerar que en la presente altura de los tiempos la oralidad primaria e inmediata, sin contacto con la escritura, prácticamente no existe, salvo como señala Zumthor (1989), es posible encontrarla solo en las sociedades desprovistas de todo sistema de simbolización gráfica, o bien en los grupos muy aislados o analfabetos.

Lo interesante de los estudios de narraciones orales es que permiten realizar observaciones de significado a partir de la interacción social, pero no solo en nivel de observación de la acción humana, sino en la necesidad de conocer los significados más profundos que surgen de quienes participan: "Se trata en verdad de una racionalidad distinta, propia, más que de cada relato en particular de la cultura que lo contiene, la que descansa a su vez en un sistema diferente de valores, pues ninguna racionalidad funciona en el vacío: solo dentro de un determinado marco axiológico algo puede ser considerado irracional o poco racional. Toda cultura establece relaciones jerárquicas entre las cosas, y es esta escala lo que determina la racionalidad de los actos y la proporción que guarda uno con otro, fundamentalmente para la comprensión del relato" (Colombres, 2005:49).

Desde la mirada cronológica, se trata de narratividades biográficas, entendidas como experiencias personales mediatizadas por una trama, que son parte de una comunidad temporal en su conexión social, distinción que importa subrayar, pues significa considerar las particularidades, las maneras de entender el mundo y la vida desde las vertebraciones culturales de cada grupo como parte de una identidad narrativa tanto individual como social. En las narraciones se nos abre un camino que conduce a las honduras ontológicas de aquellos universos simbólicos que acompañan al hombre y a los pueblos, como bagaje que el hombre ha metabolizado generacionalmente y que expresan algo importante acerca de la vida personal y colectiva:

“...el mundo del saber tradicional. Este es el mundo del metabolismo de la infancia, ordenándose a la medida del deseo abierto al afán de búsqueda, sin prejuicio ante lo extraño, ante lo otro; mundo del ser que explora el espesor del mundo sentido de otro modo, que hace el laberinto 
imaginario del mundo de afuera, sabiendo que es también el mundo de adentro" (Sepúlveda, 1983:14).

Se establecen analogías entre la realidad y sus signos con los de la vida comunitaria, razón por la cual es frecuente observar cómo la naturaleza se humaniza y cuando lo inanimado e inerte cobra vida; se metaforizan las explicaciones mediante encantamientos, sucesos extraordinarios, sacralizaciones, etc. "Para el ojo del hombre, la naturaleza es inerte y, al mismo tiempo, es vida que da vida, adquiere poder y se hace sobrenatural y, en consecuencia, tiene injerencia en la vida del hombre y de la sociedad. La naturaleza, la sociedad y el pensamiento son una realidad imbricada e inentendible una sin las otras, aisladamente. Es decir, están concatenadas dialécticamente" (García, 1991:219).

La vida humana se conecta con lo que acontece en la naturaleza, en la comunidad y en la generación de un conocimiento desde el cual narra incorporando lo que su experiencia cultural y cotidiana le señala. Esta dinámica de interactividad posibilita una relación entre el sujeto narrante y lo externo a él, es decir, existe un cierto funcionamiento análogo entre el mundo personal y las cosas del mundo natural, por consiguiente, es un narrador informado. No hace referencias en el relato a asuntos externos a él, sino que los sucesos son los elementos constitutivos de las metáforas y metonimias vinculantes. Sin embargo, es a partir de esas metáforas que se construye el imaginario tanto individual como colectivo, permitiendo propiciar las conexiones que movilizan el pensamiento a su mejor adecuación y abarcando distintas posibilidades (posibilidades ciertas), que al propalarse dan lugar a un imaginario de un determinado grupo.

“Así, por ejemplo, la piedra puede adquirir sentimiento, se humaniza y se vuelve sobrenatural si está al servicio de una causa noble; lo mismo ocurre con el hombre que carece de sentimiento, se deshumaniza, se hace insensible y se vuelve piedra. En otros términos, según los casos, se mantiene o se invierte el papel funcional de los objetos que simbolizan una acción o una situación. Lo sensible se hace insensible y lo insensible sensible como lo inerte se hace vida y la vida inerte. Esta simbolización, interpretación y explicación en la cultura popular es constante" (García, 1991:219).

Una lectura de estas narraciones nos aportan información relevante acerca del universo de valores, como se observa en el relato que se presenta a continuación, en que existe un comportamiento estético (y ético) en la construcción del relato como parte de una vocación creadora en el modo de organizar la vida, cuajada de sentido en cada una de las acciones: "Esta capacidad creadora del hombre no se reduce [ por otra parte ] a su conciencia ni a la sola razón. A diferencia de lo que plantea el racionalismo ilustrado, esas 
capacidades incluyen también a sus sentidos, afectos, sentimientos, valores, intuiciones y capacidades extrasensoriales" (Parker, 2006:19).

\section{EL TIEMPO EN LOS RELATOS}

Al realizar una lectura estética en el modo que tiene el hombre de construir sus narraciones, resulta muy necesario observar que, por lo general, la dimensión del tiempo que se vivencia tiene más que ver con las experiencias vitales que con referencias cronológicas, de tal manera que el tiempo adquiere una dimensión humana más potente: “...el tiempo mismo se torna humano en la medida que es articulado sobre un modo narrativo" (Arfuch, 2010:87).

En sentido tradicional del mundo occidental-cristiano, el tiempo es entendido de manera lineal; el hombre se moviliza en sus tres ejes de pasado, presente y futuro, cada una de las cuales se vivencia y expresa de manera distinta y/o propia, sin embargo, también se dimensiona el tiempo más allá del ciclo biológico, es decir, la del tiempo trascendental: "El pueblo entiende y expresa su tiempo pasado en formas diversas, es decir, según sea el tipo de tiempo que se trate. Hay un pasado del yo personal, otro de la familia, uno comunal o de la etnia, etc. Las formas como se implican y diferencian estas tramas temporales son claves para entender lo que es la memoria colectiva, la representatividad cultural de las biografías, la horia comunal o el recorrido profundo de la historia de los pueblos en sus luchas, etc. Y cómo estas se expresan..." (Flores, 1991:102).

El modo como el pueblo construye su pasado lo es desde dos miradas: una que es directamente vivencial, por ejemplo, las referidas a fenómenos naturales, un terremoto, una riada, una peste, etc.; la segunda que es a nivel de un plano de mayor elaboración cultural, por ejemplo, las adivinanzas, cuentos, chascos, apodos, que son puestos en funcionamiento desde una matriz simbólica, que al ser ideologizados, teologizados, interpretados, etc., les otorga la movilidad social con un tiempo que es constructor de sentido. En el caso de los relatos, como el que se presenta, cuando el(la) narrador(a) se expresa lo hace a partir del conocimiento y manejo del sentido del pasado, ya sea de la vivencia del grupo familiar o de la comunidad y del saber acumulado.

Sin perjuicio de lo anterior, este tipo de narraciones, si bien tienen un anclaje con predominio de pasado, contienen dimensiones de interpretación de presente, desde las cuales se asume una posición ante lo que ve y lo que ocurre; ante lo visible e invisible (el mundo y el transmundo) y es, precisamente, en esta acción con alcances comunitarios en los que se producen los ajustes por un mejor decir de sentido, toda vez que la actitud narrativa se moviliza a base de una intertextualidad en la medida que existe como referente el mundo, por ejemplo, el mundo evangélico en donde todo opera según un orden valórico; de 
hecho la realidad se presenta como un espacio de convergencia y en este sentido la estética opera direccionada por una ética.

Las narraciones se plantean como una manera de ver lo que pasa, cómo es percibido aquello y cuál es la actitud ante lo narrado, lo que revela la conciencia de identidad, una manera como se estructura el juicio por medio del cual se resiste a la cultura dominante. Se mira de preferencia al pasado y al presente, pues en la tradición lo que se ha hecho es más importante que lo que se pretende realizar, de allí la valorización del pasado en educación, curriculum vitae, situación económica, costumbres, es decir, todo aquello que sea más entrañable. Es un tiempo que es referente de la circunstancia vital, es decir, de las festividades, ciclos naturales y productivos y, en general, de las más disímiles situaciones cotidianas: Cfr. "nació pa' San Juan", "se enfermó pa'l tiempo de las cosechas".

\section{EL ESPACIO Y LOS SÍMBOLOS}

Las narraciones orales, ya sean cuentos, leyendas, mitos o creencias se semantizan a partir de su "espacialidad"; cada aspecto del espacio se semiotiza hasta alcanzar en algunos casos el estatuto de símbolo, principalmente en el ámbito rural e indígena, por ejemplo, una montaña, un volcán, un árbol, un río, son parte de la relación ecológica y dialogante entre el hombre y la tierra, en la que los objetos como los citados adquieren vida íntima (cultura agrocéntrica). Así como decíamos del tiempo que se entrecruzaba en sus ejes, en el caso de los espacios estos interactúan a igual nivel. El espacio de la realidad histórica del aquí y ahora se conjuntará con la realidad imaginaria, de este modo los espacios serán percibidos también como maravillosos, como realidades anímicas. Una naturaleza con personalidad, como ser viviente, en consecuencia, estará sujeta a los vaivenes cambiantes y caprichosos, constituyendo un microcosmos personificado.

El espacio será, entonces, narrable, emocional, mítico como en la Biblia; son espacios de mundos posibles en los que los seres y objetos se simbolizan en distintas direcciones, incluidos, ciertamente, los sobrenaturales; existirán otros espacios para milagros y sanaciones; espacios de sociabilidad; espacios sacralizados para la ritualidad. Los espacios de la muerte, percibida esta como una "trashumancia" a otra etapa, mientras tanto pareciera ser un espacio fronterizo, "de peaje" por el que hay que cruzar; acaso por ello los ríos se relacionan con la vida, la muerte y el destino. En la mitología griega Caronte era el barquero que transportaba a los muertos por el río Aqueronte; se le colocaba una moneda, un óbolo, en la boca del muerto para pagar el "peaje" al barquero.

Ejemplos de lo anterior es el motivo del desplazamiento y creación asociado al ave fénix como símbolo de la supervivencia por medio de la 
resurrección. Según el mito se trata de un ave milagrosa (un solo ejemplar) que hacía su nido en la palmera más alta y que se incendie con el calor de los rayos dejándose quemar, sin embargo, de las cenizas nace un fénix rejuvenecido. En otros casos el motivo de la cremación es reemplazado por el mito de la deglución de un monstruo, que simboliza el descenso al mundo de la muerte, desde el cual renace mediante un factor ayudante, tal y como se entienden las luces de acompañamiento al féretro cuya simbología es la de iluminar el camino del alma hacia el encuentro divino; además de simbolizar mediante la luz la purificación del alma.

En las narrativas orales, que es donde mejor se ejemplifica el mal, es posible encontrar una recurrencia de símbolos de orígenes como los contrastantes luz/oscuridad que se manifiesta en el relato siguiente. La oscuridad - noche-, en equivalencia a miedo, muerte. En la oscuridad todo se conjunta y en ese sentido simboliza un encuentro entre elementos opuestos que coinciden (coincidentia oppositorum). En cambio, la luz es positiva y se encuentra en lo alto, se asocia con el conocimiento y sabiduría, incluso en expresiones coloquiales: "me ha quedado claro". Los templos, iglesias, sinagogas, entre otras, inician sus ritos con la luz que se enciende para abrir caminos que separan los del mundo profano y porque se hace visible ese transmundo que se invoca, es decir, el comienzo va asociado a la luz (dar a luz). En la práctica, tanto de religiones como de sectas y hermandades, el culto es una cuestión básica y obligatoria, y los medios por los cuales se realiza la práctica cúltica está, mayoritariamente, basada en símbolos, acaso porque mediante ellos se accede a otros estadios o esferas para acercarnos a otro espacio, mundo o ser.

El Cirio Pascual que es símbolo de Cristo es encendido y bendito con la llegada del nuevo año, después de superarse el tiempo viejo, luego, lo nuevo, se saluda con luz (hoy con fuegos de artificio). En general, la religión es gran constructora de espacios para la recurrencia simbólica, incluso a todo nivel como en notas y tonos, por ejemplo J. S. Bach es un buen ejemplo de expresión de la grandeza divina predicando los mensajes bíblicos musicalmente (las trompetas simbolizando la resurrección).

\section{EL RELATO}

A continuación se transcribe un relato recopilado en la Provincia de Osorno, sector de Corte Alto, en el que se realizará una lectura desde la interpretación de sentido de sus claves simbólicas. 
"EL SIN CABEZA EN EL FUNDO EL MANZANAL"

"Mis padres vivieron toda una vida en el fundo El Manzanal, trabajando para Don Otto, luego nosotros también crecimos y comenzamos a trabajar para él. Así murió Don Otto y nosotros seguimos trabajando para su hijo, Don Klaus. Mi padre solía mencionar que cuando ellos llegaron eran unas pocas hectáreas de tierra, pero Don Otto fue ganando cada vez más y parece que hacía leso a los mapuches, y el fundo creció muy rápidamente. Así pasaron los años y Don Otto envejeció y murió, y lo miraron en la urna, pero no tenía cabeza. La gente decía que Don Otto tenía pacto con el diablo y por eso el diablo le llevó la cabeza cuando él murió.

Cuando cumplí los dieciséis me llevaron a trabajar a la casona del fundo, allí en un lado de la casa estaban todas las oficinas, al lado de nuestro dormitorio y del otro lado se encontraba la casa de los patrones. Yo ayudaba a la empleada a hacer la limpieza y le tocaba ordenar y limpiar las oficinas por la noche y luego cerraba todo con llave. Había ocasiones en que por el pasillo se veía un hombre de sombrero y manta igualito a Don Otto y a mí me daba miedo y me iba corriendo a buscar a la otra niña que me ayudaba para que me acompañase. También me tocaba apagar las luces de todas las oficinas y siempre la luz de la oficina de Don Otto se volvía a encender, incluso una noche vimos salir llamas de la oficina de Don Otto y cuando volvimos con ayuda todo estaba tranquilo. Incluso por las noches, en el pasillo, se solía escuchar que un hombre andaba a caballo y luego arrastraban las espuelas por el piso.

Todos los años al aniversario de la muerte de Don Otto se le solía ver en lo alto de una pampa, en su caballo, mirando el fundo, y lo solían ver sentado en su oficina.

Así pasaron los años y yo me fui de El Manzanal y Don Otto nunca encontró descanso, porque parece que siempre quería más".

María Inés Vivar

Edad: 76 años

Localidad: Corte Alto, Provincia de Osorno

\section{EL SENTIDO DE LAS CLAVES}

1. El primer término; el Mal se identifica en la condición humana del extranjero, el alemán, se relaciona con el Diablo —que es metáfora del mal-, asociado al tiempo de la noche, al poder de la oscuridad, lo subterráneo, el fuego. Se trata de una presentación dicotómica del mundo en el que la oscuridad es propicia para la presencia de las fuerzas del mal, que es lo que define al dueño del fundo, Don Otto. Al diablo no le está dado movilizarse en la transparencia de la luz, pues pertenece al mundo de las sombras, que no es el de la vida misma. La muchacha opone resistencia pasiva encendiendo la luz, pero 
más poderoso es el Mal, en esa oscuridad donde no se ve el rostro, ni una voz, a diferencia de las fuerzas del Bien, que sí se da a través del poder de la palabra y como imagen de luz y alma.

2. Al momento de morir: "lo miraron en la urna y no tenía cabeza". "La gente decía que tenía pacto con el diablo y por eso le llevó la cabeza", es decir, que lo que quedó en el féretro fueron los restos, la materia desechable que no sirve y por ello se desvanece, vale decir, todo aquello que no concibe ideas. La cabeza es un símbolo de poder en el que están contenidos los aspectos fundamentales de los sentidos: vista, oído, gusto y olfato. Paralelamente en la cabeza están contenidas las facultades y poderes del habla y el conjunto de datos que constituyen la identidad personal como la boca y con ella la voz, sustento y transporte de la palabra. En el caso del relato no existe una voz, solo una sombra, es decir, una persona detrás que se manifieste; existe presencia, pero sin poder. Lo que queda es solo la representación del inconsciente y de la pulsión de la muerte, en coexistencia con un imaginario religioso no desde la creencia, sino desde el ejemplo a partir de la dicotomización de la existencia entre Bien y Mal, mediante la cual se realiza la tentativa de explicar la realidad que se revela a una mujer campesina. Don Otto era poseedor en un principio de una pocas hectáreas, pero "fue ganando cada vez más y parece que hacía leso a los mapuches, así el fundo creció muy rápidamente". En este contexto la ausencia de su cabeza nos está refiriendo a su conducta transgresora, que generaba ideas fecundadoras basadas en el abuso y el engaño. El sentido del descabezamiento simboliza el Mal sustentado en un personaje usurpador, en consecuencia, es castigado en el relato, de tal modo que estará vagando sin encontrar descanso; "perder la cabeza" es algo grave y el castigo es la decapitación, ejemplo mediante el cual el hecho extraordinario del difunto sin cabeza otorga un poder de certeza al relato.

3. "...Por las noches se solía escuchar en el pasillo que un hombre andaba a caballo y luego arrastraba las espuelas por el piso". El caballo es un animal que no siempre tiene alcances de significación positiva, denota poder, briosidad, fuerza, pero que para el caso de la presente narración se trata de una fuerza que no tiene voluntad ni figura, en ese sentido constituye solo una cratofania, que se manifiesta en la creación del espacio sobrenatural que se construye en el relato en torno a la figura de Don Otto, que es espacio también de muerte. Luego, el caballo tan propio del espacio campesino, en este caso, atemoriza; trasciende su propia condición de animalidad. En la misma condición se manifiestan las espuelas con su sonoridad que adquiere una connotación maléfica; invoca el aguijoneo que se mueve en un tiempo permanente, tal como la "reaparición" de Don Otto en cada aniversario de su muerte, transfigurando de alguna manera el lugar, mediante estas irrupciones nocturnas en donde el espacio y el tiempo se sumergen en la oscuridad, pero que sí es el momento más propicio para lo 
extraordinario, en oposición a lo ordinario en donde lo habitual es la percepción y visibilización de los tiempos y espacios. En suma, en este relato el caballo no es símbolo de virilidad o heroización, sí es símbolo de la autoridad del patrón del fundo, pero desde una dimensión de la muerte (las harpías eran representadas también como yeguas).

4. La narración, que evoca una realidad en términos que los acontecimientos efectivamente habrían ocurrido, en consecuencia, son presentados testimonialmente, como expresión simbólica de un imaginario cristiano de la condena de la ambición, en el sentido que el hombre y la mujer pertenecen al mundo de la sencillez, la humildad, desarrollada en el marco de una ética de la rectitud, no alienada de la pura materialidad. Al contrario, el hijo, Klaus es la reproducción del orden establecido dentro de unos mismos parámetros morales, en la idea que un árbol malo no puede dar frutos buenos y viceversa: por sus frutos los conoceréis.

Se condena la avidez propia de quien siempre necesita y ansía crecer, al contrario que presenta la narradora que permanece en sí misma y eso significa que tiene entidad y tranquilidad cristiana, ligada a un yo de servicio. Esa tranquilidad de la que carece Don Otto que está condenado a cuidar la propiedad que ni siquiera puede gozar.

5. El condenado se configura, luego de muerto, como un alma en pena que sale de su tumba al anochecer de manera anormal, sin cabeza, por consiguiente, sin habla, imposibilitado de dar órdenes ni concebir ideas, pues su cuerpo fragmentado lo impide. La metaforización del mal hacendado se debe a sus transgresiones: "y parece que hacía leso a los mapuches...", a normas de vida que en el relato tienen otra penalidad, como es el desprendimiento de una parte del cuerpo, cuya consecuencia es el vagar eterno, y que en el mundo del relato popular se castiga simbólicamente en este terrateniente. El motivo de la acefalía es una señal de mal, de primitivismo en términos de violencia como categoría de terror, representando como la fuerza depredadora que regresa. Existe una pulsión que provoca que el miedo retorne, percibiéndose el narrador como parte de la indefensión en el espacio disoluto del miedo.

En el relato nos parece que la intención consiste en presentar un caso de existencia desde la experiencia del Mal, y eso significará formularlo desde la fragilidad del hombre expresada con un lenguaje simbólico; visto así, develar el mal, como ocurre en el relato, no es otra cosa que un ejercicio de interpretación en el sentido que lo dicho se expresa lingüísticamente con alcances éticos. Aquí el símbolo del Mal es denotativo, cabeza cercenada, "castrada", carente de sentidos, solo como sombra de terror, pero siendo presencia sin poder, como consecuencia física directa en tanto castigo que se paga por unas transgresiones. El Mal es una impureza (mancha en Ricoeur), que en términos cristianos se expresa como pecado, que opera como atadura interna a la condición humana. 
El Mal se presenta desde su condición ética, y el relato, si bien da cuenta de un proceder del alemán anómalo, propende hacia la recuperación de un sentido perdido. Las transgresiones posibilitan la interiorización creciente del mal y al profundizarlo desde la propia conciencia, es posible el desarrollo de una conciencia moral. Es decir, por medio del relato es posible rastrear las recurrencias de la comunidad; rastrear los caminos y recodos desde donde se vive, se transita y se vive, que es, en definitiva, el punto desde donde habla el pueblo. En tal caso el relato es una prolongación de las matrices míticas donde se movilizan las estructuras profundas del pueblo, lo que nos lleva a pensarlo como una cuestión de variantes e invariantes que subyace en lo profundo, que se formula en un abanico más o menos amplio — en este caso un relato- según la vitalidad del contenido circulante.

Nos parece que el planteamiento del relato presentado propone unas determinadas condiciones empíricas de la vida desde una ética del comportamiento, que permite oponer la dicotomía bien/mal. El Mal es una forma de finitud, y que en el alemán es dramático por su vagar sin descanso y disfrute de lo que tenía, pero este Mal se convierte en una característica del conocimiento para y sobre lo humano, al mismo tiempo que conjuga los grados de conciencia y sus formas de representación. El mal comportamiento de Don Otto está "atestiguada" por la asunción de un yo desde la autenticidad de la historia en la voz de su protagonista, como parte de la narración desde un espacio biográfico y desde allí, probablemente, se articulen lazos de socialización e ideales de comunidad, momento en el cual pueden considerarse como relatos para la existencia desde una dimensión articulada entre el mundo relatado y el mundo del oyente, con una mayor tensión hacia el mundo que hacia el texto.

\author{
Universidad de Los Lagos* \\ Departamento de Humanidades y Arte \\ Avda. Alcalde Fuchslocher 1305. Osorno (Chile) \\ bcardena@ulagos.cl
}




\section{OBRAS CITADAS}

Arfuch, Leonor. El espacio biográfico. Dilemas de la subjetividad contemporánea. Buenos Aires: F. C. E., de Argentina S.A., 2010.

Colombres, Adolfo. Marco Teórico para el abordaje y Desarrollo de la Tradición Oral y la Literatura Popular de Nuestra América. Quito: Instituto Andino de Artes Populares, s/impresión, 2005.

Durand, Gilbert. La imaginación simbólica. Buenos Aires: Amorrortu, 1971.

Echeverría, Jaime et al. "La decapitación como Símbolo de Castración entre los Mexicas - y Otros Mesoamericanos-y sus connotaciones Genéricas", en Revista Estudios de Cultura Náhualt, N 41, México, UNAM, Instituto de Investigaciones Históricas, 2010:137-165.

Eliade, Mircea. Lo sagrado y lo profano. Madrid: Guadarrama, 1973.

Flores, José C. (s/j). "Hacia la Conformación de un Método HistóricoProyectivo - Progresivo en el Estudio de la Cultura Popular Andina", en Folklore: Bases Teóricas y Metodológicas. Perú, Comité Permanente de Conceptualización del Folklore, Lluvia Editores, 1991:99-105.

García, Juan J. "Lo holístico, lo histórico y proyectivo en las tradiciones populares andinas", en Folklore: Bases Teóricas y Metodológicas. Perú, Comité Permanente de Conceptualización del Folklore: Lluvia Editores, 1991:218-228.

Klein, Irene. La narración. Enciclopedia Semiológica. Buenos Aires: Eudeba, 2007.

Ong, Walter. Oralidad y escritura. Tecnologías de la palabra. México: F. C. E., 1996.

Parker, Cristian. Cultura. Cuadernos de Ideas 4. Santiago de Chile: Ediciones Universidad Católica Silva Henríquez, 2006:7-37.

Schwarz, Fernando. Mitos, Ritos, Símbolos. Antropología de lo sagrado. Buenos Aires: Biblos, 2008.

Sepúlveda, Fidel. "Notas para una Estética del Folklore", en Aisthesis v.n 15. Santiago, PUC, Depto de Estética, 1986:13-18.

Zumthor, Paul. La letra y la voz. Madrid: Cátedra, 1989. 